\title{
Leptospirosis in the western Indian Ocean islands: what is known so far?
}

Amélie Desvars ${ }^{1,2}$, Alain Michault ${ }^{2}$ and Pascale Bourhy ${ }^{3^{*}}$

\begin{abstract}
In the past decade, leptospirosis has emerged as a major zoonosis with a worldwide distribution. The disease is caused by bacteria of the genus Leptospira. The western Indian Ocean includes more than one hundred tropical or subequatorial islands where leptospirosis constitutes a major public health problem. The clinical signs of the human disease are generally similar to an influenza-like syndrome, but acute forms of the disease are reported and mortality remains significant in this region. In animals, clinical forms are mainly asymptomatic but leptospirosis reduces the fertility of livestock, resulting in economic losses. The data available about human and animal leptospirosis in the western Indian Ocean islands are diverse: human leptospirosis has been extensively studied in Reunion Island, Mayotte, and the Seychelles, whereas the human clinical disease has never been described in Madagascar, Comoros, Mauritius, or Rodrigues, mainly because of the deficiency in appropriate medical and diagnostic structures. The rat is recognized as the major reservoir host for the bacteria on all islands, but recent data from Reunion Island indicates that almost all mammals can be a source of contamination. The incidence of leptospirosis in humans is highly seasonal, and linked to the rainy season, which is favorable for the environmental maintenance and transmission of the bacteria. The epidemiology of leptospirosis is fully island-dependent, related to the number of mammalian species, the origins of the introduced mammalian species, the relationships between humans and fauna, and environmental as well as cultural and socio-economic factors.
\end{abstract}

\section{Table of contents}

1. Introduction

2. Regional context

3. Known Leptospira hosts in the western Indian Ocean islands

3.1 Animal hosts

3.2 Human leptospirosis in the western Indian Ocean islands

4. Clinical presentation of leptospirosis and epidemiological risk factors in the western Indian Ocean islands

4.1 Clinical presentations

4.2 Risk factors of contamination in animals and humans

5. Molecular epidemiology and genetic characterization of circulating strains

\footnotetext{
* Correspondence: pbourhy@pasteur.fr

${ }^{3}$ Institut Pasteur, Unité de Biologie des Spirochètes, Centre National de Référence de la Leptospirose, Paris, France

Full list of author information is available at the end of the article
}

6. Conclusions

7. Abbreviations

8. Competing interests

9. Authors' contributions

10. Acknowledgements

11. References

\section{Introduction}

Leptospirosis, a bacterial disease caused by pathogenic species from the genus Leptospira (phylum Spirochaetes), is probably the most widespread zoonotic disease in the world [1] and is most commonly found in tropical and subtropical countries [2,3]. Leptospirosis is maintained by the persistent colonization of the renal tubules of carrier animals, and it appears that almost all mammals are susceptible to be natural carriers of Leptospira [4-6]. An infected animal can remain symptom-free and shed infectious organisms in its urine, either transitorily or for its entire lifetime [5,7]. Humans can be infected directly by contact with the urine of an infected animal or indirectly from the contaminated environment [5]. The survival of the bacterium outside the host generally requires humid and warm conditions [7].

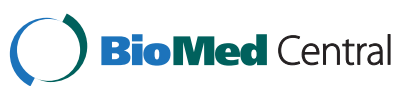


The genus Leptospira comprised the saprophytic subgroup (with six known species), the pathogenic subgroup (nine species), and the intermediate subgroup (five species) the pathogenicity of which remains unclear [8]. The pathogenic species comprise more than 250 serovars belonging to approximately 24 serogroups based on agglutinating lipopolysaccharide antigens [8]. This serological classification is widely used in veterinary and human epidemiological studies but remains incompatible with more modern molecular classification (Table 1) [5]. The most widely used test is the microscopic agglutination test (MAT) in which patient sera are mixed with antigen suspensions of live Leptospira and examined by dark-field microscopy for agglutination [5]. This test, on which much of our data is based, suffers from several limitations (reproducibility, restricted panels of antigens, lack of sensitivity, and specificity), and a comparison between different studies conducted in different places is currently not possible [9-11]. Genetic characterization of isolates involves various genomic methods, such as sequencing of $16 \mathrm{~S}$ rRNA gene, pulsed-field gel electrophoresis (PFGE), multi-locus sequence typing (MLST), or multiple-loci variable number tandem repeat (VNTR) analysis (MLVA) [8].

The western Indian Ocean islands are closed ecological ecosystems where the biocenosis involves both endemic and introduced host species and pathogens. This "composite" biodiversity [12], and the particularities of local ecological conditions as well as agricultural and cultural practices, result in divergences in the epidemiology of the disease between islands [13]. Data about animal leptospirosis in the western Indian Ocean islands remain scarce. This review is aimed at describing the diversity and the distribution of the pathogenic leptospiral serovars/serogroups as well as the epidemiological features of human and animal leptospirosis in some islands of the western Indian Ocean area. Data on leptospirosis have not been published or are not available for all of the islands in this region, and consequently the review addresses mainly the islands of Madagascar, the Seychelles, Mayotte, and Reunion.

$\begin{aligned} & \text { Table } 1 \text { Distribution of the serogroups cited in the text } \\
& \text { within Leptospira }\end{aligned}$
\begin{tabular}{ll} 
Genomomospecies & Serogroups \\
\hline L. interrogans & $\begin{array}{l}\text { Icterohaemorrhagiae, Canicola, Pomona, Australis, } \\
\text { Autumnalis, Pyrogenes, Grippotyphosa, Sejroe, Mini }\end{array}$ \\
L. borgpetersenii & $\begin{array}{l}\text { Hebdomadis, Tarassovi, Australis, Autumnalis, } \\
\text { Pyrogenes, Sejroe, Mini, Ballum }\end{array}$ \\
L. kirschneri & $\begin{array}{l}\text { Icterohaemorrhagiae, Canicola, Pomona, Australis, } \\
\text { Autumnalis, Grippotyphosa }\end{array}$ \\
L. noguchii & Australis, Autumnalis, Pyrogenes, Pomona \\
L. fainei & Hurstbridge
\end{tabular}

The table shows the serogroups most often found in human clinical cases and in animals by epidemiological surveys (from [5]).

\section{Regional context}

The western Indian Ocean counts 21 inhabited groups of islands belonging to 12 countries (Figure 1). The terrestrial surface areas of the western Indian Ocean islands are between $<1 \mathrm{~km}^{2}$ (Bassas da India) and $587041 \mathrm{~km}^{2}$ (Madagascar). Most islands of this region have a tropical climate with two main seasons: a hot and rainy season ("austral summer"), and a dry season ("austral winter"). In the Seychelles, the climate is subequatorial with more than $80 \%$ of humidity all year round.

\section{Known Leptospira hosts in the western Indian Ocean islands}

\subsection{Animal hosts}

Mammalian biodiversity is poor in the volcanic islands of the western Indian Ocean and all mammals currently present, except bats, have been introduced. However, Madagascar is one of the most striking hotspots of biodiversity on Earth where most of the fauna is endemic [14]. Table 2 summarizes the various Leptospira hosts studied in the western Indian Ocean region. Leptospirosis is probably endemic in the mammalian species of the western Indian Ocean islands Table 2 [15-17]. In Mayotte and Reunion Island, serological surveys showed a high seroprevalence of leptospirosis in non-vaccinated (stray and domestic) dogs [15,17] and dogs have been demonstrated to be renal carriers and urinary shedders of Leptospira on the Reunion Island [17]. In Reunion, the seroprevalence of the disease in dogs has not varied substantially since 1980, and the Canicola serogroup has been described as the main serogroup infecting dogs; Icterohaemorrhagiae is the second most frequent in dogs $[17,18]$. By contrast, in Mayotte, the serogroup Mini (the main serogroup implicated in human cases) has most frequently been identified by serology in stray and domestic non-vaccinated dogs [15].

Leptospirosis has been known since 1980 to be a major infectious disease in cattle in Reunion Island [19] and in 2003, a study showed that serogroups Sejroe and Hebdomadis were major causes of abortion in dairy cattle [39]. Sejroe was reported to be the main serogroup circulating in beef and dairy cattle in Reunion Island in 2009 [17], whereas in Mayotte, cattle are mostly infected by serogroup Mini (National Reference Center for Leptospirosis, France, unpublished data). The original Hebdomadis serogroup is divided into three separate serogroups according to their serological affinities: Hebdomadis, Sejroe and Mini [43]. Given the absence of isolation data and the antigens used in serological studies, the seroreactivity to Sejroe, Mini, and Hebdomadis serogroups in cattle could be cross-reactions hiding a serological response to only the serovar Hardjo, for which cattle are the maintenance hosts [7]. 


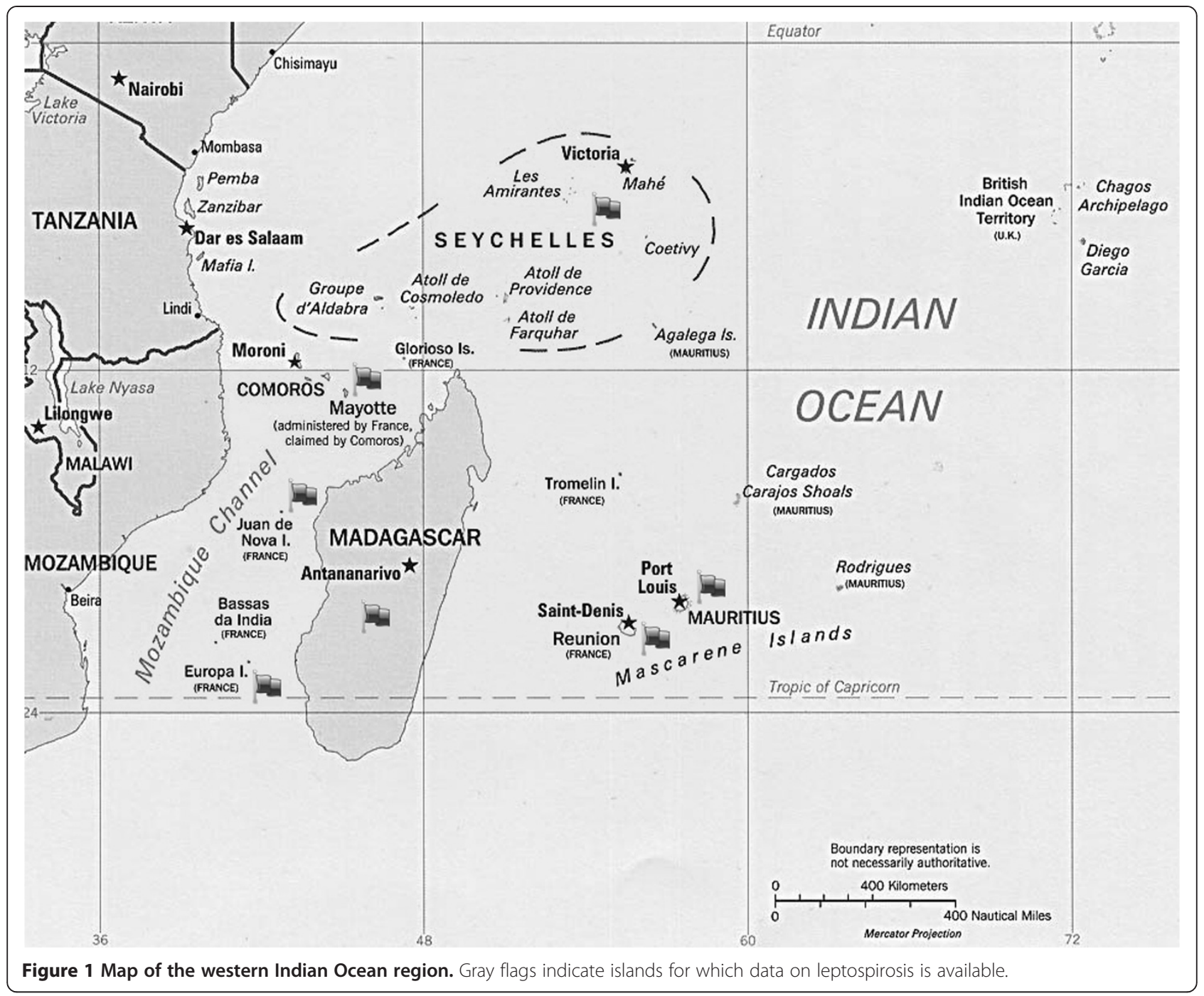

Bovine and pig leptospirosis has long been suspected in Madagascar [44] but the renal carriage of Leptospira has never been documented in these species [40]. Nevertheless seroprevalence in apparently healthy cattle and pigs was reported in 1968 in the south region of the island, with the predominance of the Grippotyphosa serogroup [20]. Desvars et al. [17] reported that in Reunion Island, serogroup Pyrogenes and Panama are the most prevalent serogroups found by MAT in goats, Rusa deer, and pigs whereas they are rarely reported in diagnosed patients [45].

Serological surveys of the insectivorous tenrec (Tenrec ecaudatus) in Reunion Island report seroprevalences of between $13.2 \%(5 / 38)$ [17] and 92\% (34/37) [38] in this species, probably depending on the geographical area of sampling and/or age of the animals. Leptospira could not be evidenced in tenrec kidney or urine, suggesting that this species is probably not a chronic reservoir host for the disease [17].
The epidemiological role of bats in the transmission of Leptospira attracts more and more scientific interest [46-53]. In Madagascar, antibodies to Leptospira could not be evidenced in the fruit bat Pteropus rufus [54,55], but recently, pathogenic Leptospira spp. were found in bats, in Madagascar and Union of Comoros [42]. In Mayotte, a recent study reported a seroprevalence of $10.2 \%$ (5/49) in Pteropus seychellensis with Pyrogenes and Grippotyphosa as infecting serogroups [15]. The free-tailed bat (Mormopterus francoismoutoui, family Molossidae) is a urinary shedder of Leptospira [17]. Nevertheless, the zoonotic role of bats species in the transmission of leptospirosis to humans remains uncertain.

Serological evidence of leptospirosis has been reported in lemurs from Mayotte but at a low seropositive rate $(2 \%, 1 / 50)$ [15]. This low rate is probably due to the arboreal lifestyle of these animals minimizing their contact with contaminated water or soil. Sensitivity to leptospirosis differs greatly between non-human primates [56-59]. We 
Table 2 Potential hosts of Leptospira in the western Indian Ocean islands.

\begin{tabular}{|c|c|c|c|c|c|c|}
\hline Species & Geographic location & $\begin{array}{l}\text { Sensitive } e^{(1)}(\mathrm{S}) \text { or } \\
\text { resistant }^{(2)}(\mathrm{R})\end{array}$ & Main clinical signs & $\begin{array}{l}\text { Asymptomatic } \\
\text { chronic shedding }\end{array}$ & Economic significance & $\begin{array}{l}\text { Existing data on } \\
\text { leptospirosis in the } \\
\text { Indian Ocean region }\end{array}$ \\
\hline \multicolumn{7}{|l|}{ Primates } \\
\hline Humans & All islands & $\begin{array}{l}\text { S (asymptomatic } \\
\text { forms are frequent) }\end{array}$ & $\begin{array}{l}\text { Fever, myalgias, headache, chills, oliguria/anuria, } \\
\text { jaundice, conjunctive suffusions, aseptic meningitis, } \\
\text { hemorrhages, skin rash, renal and hepatic failure, } \\
\text { severe pulmonary hemorrhagic syndrome }\end{array}$ & Yes & $\begin{array}{l}\text { Medical costs, absence } \\
\text { from work, mortality }\end{array}$ & {$[19-35]$} \\
\hline Brown lemur (Eulemur fulvus) & Mayotte, Madagascar & $\mathrm{Nd}$ & $\mathrm{Nd}$ & $\mathrm{Nd}$ & $\mathrm{Nd}$ & {$[15]$} \\
\hline $\begin{array}{l}\text { Crab-eating macaque (Macaca } \\
\text { fascicularis) }\end{array}$ & Mauritius & $\mathrm{Nd}$ & $\mathrm{Nd}$ & $\mathrm{Nd}$ & $\mathrm{Nd}$ & No \\
\hline $\begin{array}{l}\text { Mongoose lemur } \\
\text { (Eulemur mongoz) }\end{array}$ & Comoros, Madagascar & $\mathrm{Nd}$ & $\mathrm{Nd}$ & $\mathrm{Nd}$ & $\mathrm{Nd}$ & No \\
\hline \multicolumn{7}{|l|}{ Rodents } \\
\hline Black rat (Rattus rattus) & All islands & $R$ & Absent & Yes & $\begin{array}{l}\text { Cost of control (traps, } \\
\text { poison, time) }\end{array}$ & {$[15,17,36,37]$} \\
\hline Norway rat (R. norvegicus) & $\begin{array}{l}\text { Reunion, Mauritius, } \\
\text { Seychelles, Madagascar }\end{array}$ & $\mathrm{R}$ & Absent & Yes & $\begin{array}{l}\text { Cost of control (traps, } \\
\text { poison, time) }\end{array}$ & {$[17,36]$} \\
\hline $\begin{array}{l}\text { Domestic mouse (Mus } \\
\text { musculus) }\end{array}$ & All islands & $\mathrm{R}$ & Absent & Yes & $\begin{array}{l}\text { Cost of control (traps, } \\
\text { poison, time) }\end{array}$ & {$[17,36]$} \\
\hline \multicolumn{7}{|l|}{ Terrestrial insectivores } \\
\hline Shrew (Suncus murinus) & $\begin{array}{l}\text { Mauritius, Reunion, } \\
\text { Comoros, Madagascar }\end{array}$ & $\mathrm{R}$ & Absent & Yes & $\begin{array}{l}\text { Cost of control (traps, } \\
\text { poison, time) }\end{array}$ & {$[17,36]$} \\
\hline Tenrec (Tenrec ecaudatus) & $\begin{array}{l}\text { Reunion, Mayotte, } \\
\text { Comoros, Mauritius, } \\
\text { Seychelles, Madagascar }\end{array}$ & $\mathrm{Nd}$ & $\mathrm{Nd}$ & Not proved & $\mathrm{Nd}$ & {$[17,38]$} \\
\hline \multicolumn{7}{|l|}{ Carnivores } \\
\hline $\begin{array}{l}\text { Small Indian civet (Viverricula } \\
\text { indica) }\end{array}$ & Mayotte, Madagascar & $\mathrm{Nd}$ & $\mathrm{Nd}$ & $\mathrm{Nd}$ & $\mathrm{Nd}$ & {$[37]$} \\
\hline Dog(Canis lupus familiaris) & All islands & $\mathrm{R}$ or $\mathrm{S}^{*}$ & $\begin{array}{l}\text { Fever, oliguria/anuria, jaundice, haemorrhages, } \\
\text { renal and hepatic failure }\end{array}$ & Yes & $\begin{array}{l}\text { Cost of control of the } \\
\text { stray populations }\end{array}$ & {$[15,17,19]$} \\
\hline Cat (Felis catus) & All islands & $\mathrm{R}$ or $\mathrm{S}^{*}$ & Mild, non-specific signs & Yes & $\begin{array}{l}\text { Cost of control of the } \\
\text { stray populations }\end{array}$ & {$[17]$} \\
\hline \multicolumn{7}{|l|}{ Livestock } \\
\hline Cattle (Bos taurus) & All islands & $\mathrm{R}$ or $\mathrm{S}^{*}$ & Reproductive failure & Yes & $\begin{array}{l}\text { Poor reproductive results, } \\
\text { abortion, neonatal } \\
\text { morbidity }\end{array}$ & $\begin{array}{l}{[17,19,20,37,39-41]} \\
\text { Pasteur Institute } \\
\text { (unpublished data) }\end{array}$ \\
\hline Goat (Capra hircus) & All islands & $\operatorname{Ror} S^{*}$ & Reproductive failure & Yes & $\begin{array}{l}\text { Poor reproductive results, } \\
\text { abortion, neonatal } \\
\text { morbidity }\end{array}$ & {$[17,37]$} \\
\hline
\end{tabular}


Table 2 Potential hosts of Leptospira in the western Indian Ocean islands. (Continued)

Rusa deer (Timorensis rusa) Reunion, Mauritius $\quad \mathrm{R} \mathrm{or} \mathrm{S*}^{*}$ Reproductive failure

Yes

Poor reproductive results, [17]

abortion, neonatal

morbidity

Equine

\begin{tabular}{llll}
\hline Horse (Equus ferus) $\quad$ All islands & R or S* Acute form, reproductive failure, chronic uveitis & Nd & $\begin{array}{l}\text { Cost of veterinary care, } \\
\text { abortion, neonatal } \\
\text { morbidity }\end{array}$
\end{tabular}

Bats

\begin{tabular}{|c|c|c|c|c|c|c|}
\hline $\begin{array}{l}\text { Free-tailed bat (Mormopterus } \\
\text { francoismoutoui) }\end{array}$ & Reunion & Probably $\mathrm{R}$ & $\mathrm{Nd}$ & Yes & $\mathrm{Nd}$ & {$[17]$} \\
\hline $\begin{array}{l}\text { Seychelles flying-fox (Pteropus } \\
\text { seychellensis) }\end{array}$ & $\begin{array}{l}\text { Mayotte, Comoros, } \\
\text { Seychelles }\end{array}$ & Probably R & $\mathrm{Nd}$ & $\mathrm{Nd}$ & $\mathrm{Nd}$ & {$[15,37]$} \\
\hline $\begin{array}{l}\text { Peters's wrinkle-lipped bat } \\
\text { (Mormopterus jugularis) }\end{array}$ & Madagascar & Probably R & $\mathrm{Nd}$ & $\mathrm{Nd}$ & $\mathrm{Nd}$ & {$[42]$} \\
\hline $\begin{array}{l}\text { Madagascar free-tailed bat } \\
\text { (Otomops madagascariensis) }\end{array}$ & Madagascar & Probably $\mathrm{R}$ & $\mathrm{Nd}$ & $\mathrm{Nd}$ & $\mathrm{Nd}$ & {$[42]$} \\
\hline $\begin{array}{l}\text { Trouessart's trident bat } \\
\text { (Triaenops furculum)s }\end{array}$ & Madagascar & Probably $\mathrm{R}$ & $\mathrm{Nd}$ & $\mathrm{Nd}$ & $\mathrm{Nd}$ & {$[42]$} \\
\hline $\begin{array}{l}\text { Trident bats (Triaenops } \\
\text { menamena) }\end{array}$ & Madagascar & Probably R & $\mathrm{Nd}$ & $\mathrm{Nd}$ & $\mathrm{Nd}$ & {$[42]$} \\
\hline $\begin{array}{l}\text { Glen's long-fingered bat } \\
\text { (Miniopterus gleni) }\end{array}$ & Madagascar & Probably R & $\mathrm{Nd}$ & $\mathrm{Nd}$ & $\mathrm{Nd}$ & {$[42]$} \\
\hline Miniopterus griffithsi & Madagascar & Probably $\mathrm{R}$ & $\mathrm{Nd}$ & $\mathrm{Nd}$ & $\mathrm{Nd}$ & {$[42]$} \\
\hline Miniopterus mahafaliensis & Madagascar & Probably $\mathrm{R}$ & $\mathrm{Nd}$ & $\mathrm{Nd}$ & $\mathrm{Nd}$ & {$[42]$} \\
\hline $\begin{array}{l}\text { Malagasy mouse-eared } \\
\text { bat (Myotis goudoti) }\end{array}$ & Madagascar & Probably R & $\mathrm{Nd}$ & $\mathrm{Nd}$ & $\mathrm{Nd}$ & {$[42]$} \\
\hline $\begin{array}{l}\text { Comoro rousette (Rousettus } \\
\text { obliviosus) }\end{array}$ & Comoros & Probably R & $\mathrm{Nd}$ & $\mathrm{Nd}$ & $\mathrm{Nd}$ & {$[42]$} \\
\hline $\begin{array}{l}\text { Western Seychelles Free-tailed } \\
\text { bat (Chaerephon pusillus) }\end{array}$ & Mayotte, Comoros & Probably R & $\mathrm{Nd}$ & $\mathrm{Nd}$ & $\mathrm{Nd}$ & {$[42]$} \\
\hline Miniopterus griveaudi & Comoros, Madagascar & Probably $\mathrm{R}$ & $\mathrm{Nd}$ & $\mathrm{Nd}$ & $\mathrm{Nd}$ & {$[42]$} \\
\hline
\end{tabular}


could also hypothesize that lemurs are highly sensitive to leptospirosis such that infected animals die (as demonstrated in the squirrel monkey, Saimiri sciureus, and the marmoset, Callithrix jacchus $[56,58,59])$. Thus the contribution, if any, of primates in the transmission of leptospirosis in Mayotte, Anjouan, Moheli, and Mauritius still needs to be elucidated.

All published studies confirm that the black rat is the major reservoir host for Leptospira in Europa and Juan de Nova [60], Mayotte (where the Norway rat is absent) [15], Reunion Island [17], and Madagascar [36]. In Reunion Island and Madagascar, the Norway rat, the shrew, and the domestic mouse have also be shown to be renal carriers and/or urinary shedders of Leptospira $[17,36]$. In Reunion Island, the major serogroup identified in the rat is Icterohaemorrhagiae, but other serogroups also seem to circulate (Canicola, Sejroe) [17]. In Mayotte, the Mini serogroup is the main circulating serogroup in $R$. rattus and there is strong evidence that the black rat population is the major reservoir of Leptospira and source of its transmission to humans [15].

3.2. Human leptospirosis in the western Indian Ocean islands Acute leptospirosis has never been described in Madagascar and investigations conducted locally have failed to show the presence of the bacterium in humans. Lhuiller et al. [55] reported a low seroprevalence rate among Antananarivo inhabitants. The only autochtonous clinical case (identified in the 1950's) to be confirmed serologically had antibodies to serogroup Australis [54,61]. In 1968, Silvérie et al. [20] identified that Tarassovi, Grippotyphosa, Australis, and Hebdomadis were the most prevalent serogroups in the human population in the region of Toliara. They reported a seroprevalence of $50.8 \%(33 / 65)$ [20] which seems surprisingly high in a country where no clinical cases have been reported. Recently, one human case was diagnosed at the hospital of Mamoudzou (Mayotte) involving Leptospira kirschneri serogroup Mini and was suspected to have been imported from Madagascar [21].

The first confirmed case of human leptospirosis in the Maldives was reported in November 2000. Since then, the disease has been under national surveillance [62].

The disease has been very occasionally reported in Mauritius, but there is probably underreporting, since the epidemiological conditions are very similar to those in the neighboring Reunion Island [63]. Simon et al. [22] recently described a case of leptospirosis in a French patient who had traveled to Mauritius.

The Seychelles presents the highest incidence of leptospirosis in the western Indian Ocean area and one of the highest incidences in the world [23]. Between 1988 and 1990, the annual incidence was 60 cases per 100000 inhabitants and serogroups Icterohaemorrhagiae and Autumnalis were most frequently identified during this period [64]. In
1995-1996, the incidence of leptospirosis was estimated to be 101 per 100000 [23] and eight serogroups were identified, with Icterohaemorrhagiae and Hurstbridge (the latter commonly considered as non-pathogenic) being the main circulating serogroups.

The first publication describing human leptospirosis in Mayotte was in 1990 [24]. It reported 42 cases between 1984 and 1989 and an annual incidence of 3.83 per 100000 [24]. Recent efforts in the detection of the disease [21,25] has led to the annual incidence of leptospirosis being reevaluated, as 25 per 100 000. Mini is the major serogroup responsible for human clinical cases in Mayotte whereas Icterohaemorrhagiae has never been isolated from patients in Mayotte which represents a unique epidemiological situation [21]; the other Leptospira serogroups identified in patients are Pyrogenes, Grippotyphosa, and Pomona.

In Reunion Island, the annual number of human cases of leptospirosis has varied little since 1970, with an average of 40 cases per year between 1970 and 1979 and an average of 55.7 cases between 1998 and 2008 [65] (probably due to improved diagnosis of this disease). The incidence of leptospirosis was 15.13 per 100000 in 2010 [45]. Between the 1970s and now, serogroup Icterohaemorrhagiae has been the main serogroup involved in clinical cases on Reunion Island [26-28,45,65].

\section{Clinical presentation of leptospirosis and epidemiological risk factors in the western Indian Ocean islands}

\subsection{Clinical presentations}

In humans, clinical leptospirosis has protean manifestations but generally causes a febrile illness that often, in its early phase, cannot be differentiated from other acute influenza-like fevers such as dengue, influenza, chikungunya, or malaria $[5,8]$ (Table 2). In the islands of the western Indian Ocean where human leptospirosis is found, less than $10 \%$ of hospitalized leptospirosis patients die $[21,29,66]$. In the Seychelles, about one-third of cases of leptospirosis are mild forms; two-thirds have a more severe presentation with jaundice (without liver failure) and/or acute renal failure and/or pulmonary hemorrhage [23]. In the Seychelles, during a 12-month period in 1995-1996, 8\% (6/75) of the patients with acute leptospirosis died [29]; autopsies showed that diffuse bilateral pulmonary haemorrhage was the main cause of death [29]. In Reunion Island, clinical forms of the disease in hospitalized patients are often severe [26] and pulmonary manifestations are frequent [28,67-69]. In Mayotte, 3.2\% of the hospitalized cases are fatal [21].

Leptospirosis in livestock is generally associated with reproductive failure (Table 2) [70-72] but the studies published to date do not permit evaluation of the true losses caused by the disease in dairy and beef cattle, pigs, goats, sheep, and Rusa deer in the different islands. 
Economic data of this type may encourage taking this disease into account in the management of reproduction and health problems within herds. In dogs, leptospirosis can, in some cases, cause an acute disease similar to Weil disease in humans, but mostly, the disease is asymptomatic in dogs (Table 2) [73].

\subsection{Risk factors of contamination in animals and humans}

The risk factors for acquiring leptospirosis in animals have not been studied in the western Indian Ocean region. Nevertheless, risk factors for contamination of both individual animals and herds are most probably similar to those identified in other tropical countries. [74-79].

In humans from Reunion Island and Mayotte, the risk of contamination is the highest for the 20 to 40 year-old age group $[21,26]$, and in the Seychelles, the mean age of cases is 34 years (and 53 years in fatal cases) [23]. Risk factors for acquiring leptospirosis are similar in all tropical islands. One common feature of the disease is that leptospirosis is more frequent among men than women $[21,23,28]$. This sex difference, is usually attributed to occupational and behavioral factors $[13,80]$. In the Seychelles, significant associations have been found between leptospirosis cases and activities in the forest, gardening, and refuse not collected by public services (which favors high rat population density) $[23,30]$. Washing clothes or bathing in the river, and walking barefoot, favor contamination by Leptospira [23,30] and an association between the disease and wet soil around homes has been reported in the Seychelles [23] and Reunion Island [28].

The incidence of leptospirosis in humans is affected by rainfall, particularly in tropical regions [81-83]. In Reunion Island, cases of leptospirosis are reported all year round, but epidemics mostly occur during the rainy season $[26,28,31,84]$. Therefore, despite popular belief, the peak incidence of leptospirosis in Reunion Island is not during the sugar cane harvest (July to December) [84]. This seasonality in leptospirosis cases is also observed in Mayotte where almost all cases are reported during the rainy season [21]. In the Seychelles, the relationship between rainfall and leptospirosis cases is weaker than in Mayotte or Reunion Island, probably because the rainy season is not well-defined [30]. A prediction model could be a useful tool for the identification of cases and, obviously, for predicting epidemics; this may facilitate improved diagnosis and treatment of leptospirosis to reduce lethality rates $[85,86]$. Statistical modeling should include the number of cases, meteorological factors, and data on animal and human population density (Figure 2).

\section{Molecular epidemiology and genetic characterization of circulating strains}

Genetic and serological characterization of Leptospira isolates requires considerable effort in the field with successful cultures from clinical specimens. Leptospira strains from various islands of the western Indian Ocean have been characterized, notably the Reunion Island, Mayotte and Madagascar. A clinical isolate from the Reunion Island was identified as L. interrogans serogroup Icterohaemorrhagiae (Pasteur Institute, Paris, and GHSR, unpublished data). Since 2007, more than one hundred Leptospira strains have been isolated from patient blood samples on Mayotte [21], and sequencing and MLVA, have classified these human isolates into four genomospecies: L. interrogans, L. kirschneri, L. borgpetersenii, and L. borgpetersenii group $B$, which is a newly described species [21]. Serological typing of these isolates showed that these four species are distributed into four serogroups: Mini, which represents the great majority of the infecting strains, Grippotyphosa, Pomona, and Pyrogenes. All are pathogenic to humans $[21,25]$. Sequencing of a segment of the16S rRNA gene in Leptospira detected in rat kidneys showed that the four pathogenic genomospecies responsible for human cases are also found in rats [15,21]. The genetic diversity of Leptospira in the rat population is generally low in various locations [87-90] but in Mayotte, rats carry four Leptospira genomospecies, making the genetic diversity of Leptospira strains infecting black rats on this island unique [15].

The ten isolates obtained in 2008-2009 in Madagascar from $R$. rattus and $R$. norvegicus kidneys were all identified by PFGE and MLVA as L. interrogans serogroup Canicola serovar Kuwait. This was the first isolation of a Leptospira strain on this large island [36]. The strain isolated from a patient in Mayotte returning from Nosy Be (Madagascar) was genetically closely related to clinical Leptospira isolates from Mayotte, but the MLST pattern was different, indicating that this strain did not originate from Mayotte but most probably from Madagascar [21]. Recently, the sequencing of seven fragments of the $16 \mathrm{~S}$ rRNA gene from Leptospira detected in bats from Comoros islands and Madagascar showed that three were closely related to $L$. borgpetersenii, one grouped with $L$. interrogans, and three were not associated with any described species [42]. Our studies suggest that Leptospira from Mayotte and Madagascar are closely related at the genome level, which is in agreement with previous studies [21,42]. Phylogeographic patterns support the hypothesis of a human-mediated colonization of $R$. rattus from source populations of India and the Arabian Peninsula to islands of the western Indian Ocean [91]. Independent colonization events may have occurred simultaneously in Madagascar and Grande Comore, whereas rats from Mayotte were introduced from Madagascar [91]. If Leptospira strains are introduced in a new geographical area via their hosts (in the western Indian Ocean islands, they have most probably been introduced with their preferential host Rattus sp by 


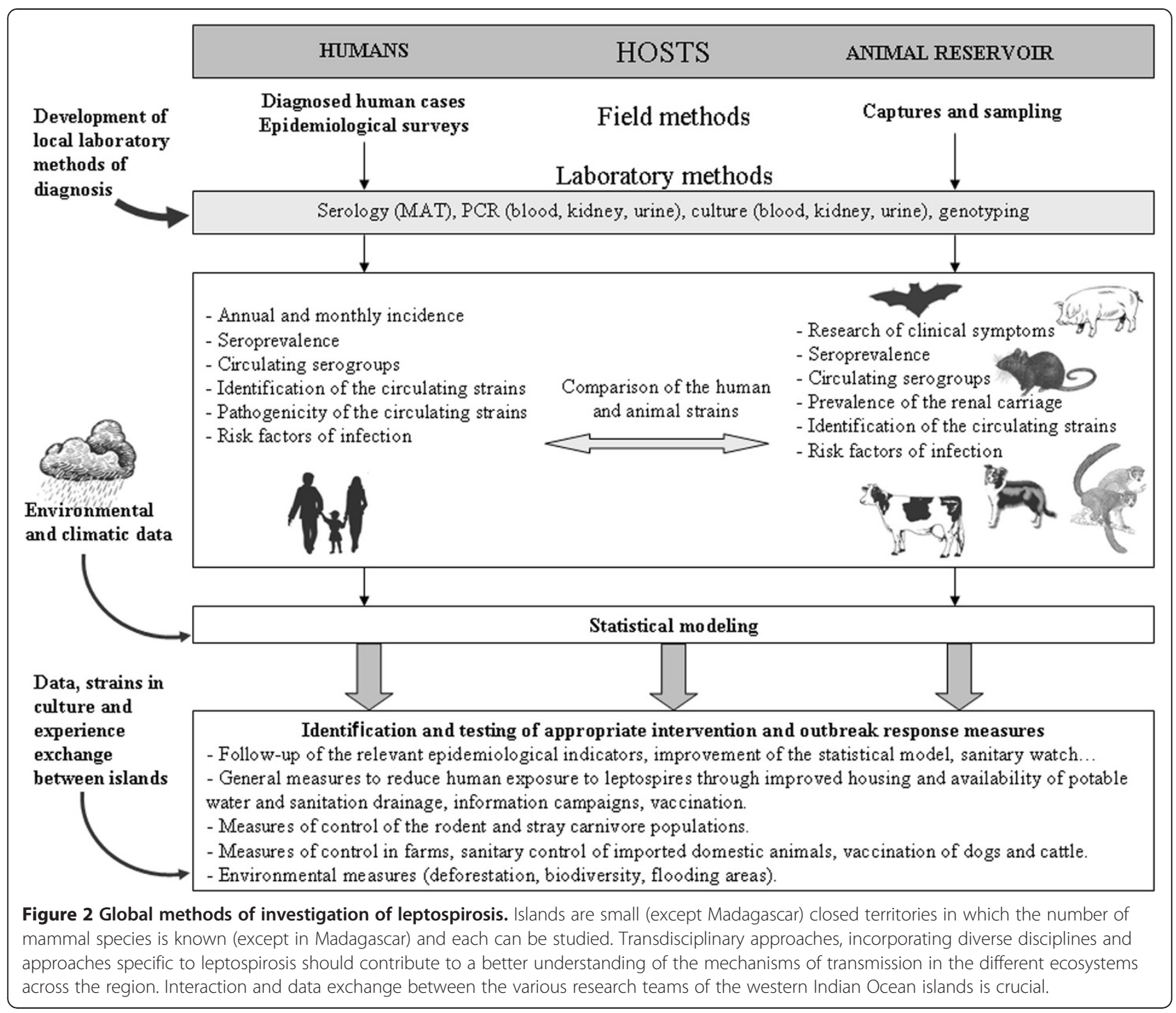

boat) [92], thus Leptospira strains identified in Mayotte are probably mainly derived from strains of Madagascar.

It would be beneficial to establish a consensus on genotyping methods, at least on the regional scale, to facilitate comparison of the circulating strains and the epidemiology of this major infectious disease. This may help the implementation of adapted island-specific and cost-effective preventive measures.

\section{Conclusions}

Leptospirosis seems endemic to all the human- and animal-inhabited islands of the western Indian Ocean region. It is supposed that Leptospira is introduced onto islands with their animal host, and that a variable number of introduced strains have adapted to the new local environment and available hosts [92]. The genetic diversity of the insular black rat populations, which have been introduced from different geographic areas
(Europe, east Africa) [91] associated with the local and isolated co-evolution of Leptospira and this preferential host may explain the island-specificity of the circulating strains $[15,17]$. Moreover, the genetic biodiversity of leptospires in a closed range, such as an island, is also affected by geography, soil, climate, biotic interactions, and anthropogenic activities [6,93]. The mammalian diversity in Madagascar provides a wide range of potential hosts for Leptospira; however, the substantial haplotype diversity of the black rat population of Madagascar [91] favors coevolution between Leptospira and several genetically different preferential hosts. Moreover, Madagascar also has a wide diversity of ecosystems. In view of these various factors, this island presents optimal conditions for genetic diversification of the genus Leptospira, as a consequence of environmental pressure and host-adaptation.

An effective surveillance system is essential for preventing and controlling outbreaks of leptospirosis [94]. Nonetheless, 
this review illustrates how knowledge about this zoonosis differs significantly among islands. In the Seychelles, human leptospirosis is probably the major known health problem in the country, but nevertheless, the animal reservoir has not been sufficiently studied.

The prevalence of the different Leptospira serogroups in a human population depends strongly on the local reservoir hosts and the strains they carry [6]. Consequently, knowledge of animal leptospirosis is essential for a better understanding of the disease in humans (Figure 2). On islands, mammalian biodiversity is closely linked with the incidence of human leptospirosis cases [12]. Since leptospirosis is a transdisciplinary problem [95], studies on the animal reservoir could be extremely useful where the epidemiology of the human disease and the human strains is well described, and should be done in parallel with collecting climatic and socioenvironmental data [95]. Predictions of global warming and an increasing frequency and severity of cyclones in the Indian Ocean due to global climate change, suggest an increased risk of flooding, and exacerbation of the disease burden from leptospirosis [1,96-100].

Studies on leptospirosis are generally conducted independently, by different research teams, and the methods of investigation and available data vary greatly between islands. As a result, studies are generally not comparable with each other, leading to a "patchwork" of isolated data. We believe that it would be beneficial to standardize the methods of diagnosis of leptospirosis, at least, throughout the western Indian Ocean region: the same panel of antigens could be used for MAT and the same primers for PCR-based investigations. The methods of typing also need to be standardized across the region to allow genetic comparison of the strains, and a regional collection of isolates would be useful (Figure 2). This will necessitate pooling resources for a better knowledge of the disease and for improving the cost-effectiveness and efficacy of preventive measures.

\footnotetext{
Abbreviations

GHSR: Groupe hospitalier sud Réunion; MAT: Microscopic agglutination test: MLVA: Multiple-loci variable number tandem repeat analysis; MLST: Multilocus sequence typing; PCR: Polymerase-chain reaction; PFGE: Pulsed-field gel electrophoresis; VNTR: Variable number tandem repeat; 16S rRNA: 165 ribosomal ribonucleic acid.
}

\section{Competing interests}

The authors declare that they have no competing interests.

\section{Authors' contributions}

$\mathrm{AD}$ and $\mathrm{PB}$ performed a study on the literature available on the subject, analyzed the retrieved information and wrote the manuscript. AM revised the manuscript critically according to their areas of expertise. All authors read and approved the final manuscript.

\section{Acknowledgments}

We thank Mathieu Picardeau (Institut Pasteur, Paris) for his suggestions during the reading for the manuscript and Azad Eshghi for his linguistic comments on the manuscript.

\section{Author details}

Unité Mixte de Recherche Contrôle des Maladies Animales Exotiques et Emergentes (UMR CMAEE), Centre de Coopération Internationale en Recherche Agronomique pour le Développement (CIRAD), Sainte-Clotilde, La Réunion, France. 'Laboratoire de Bactériologie-Parasitologie-Virologie-Hygiène, Groupe Hospitalier Sud Réunion (GHSR), Centre Hospitalier Régional (CHR), Saint-Pierre, La Réunion, France. ${ }^{3}$ Institut Pasteur, Unité de Biologie des Spirochètes, Centre National de Référence de la Leptospirose, Paris, France.

Received: 30 November 2012 Accepted: 1 August 2013

Published: 9 September 2013

\section{References}

1. Hartskeerl AR, Collares-Pereira M, Ellis WA: Emergence, control and reemerging leptospirosis: dynamics of infection in the changing world. Clin Microbiol Infect 2011, 17:494-501.

2. World Health Organization: Leptospirosis worldwide, 1999. Wkly Epidemiol Rec 1999, 74:237-242.

3. Adler B, de la Peña Moctezuma A: Leptospira and leptospirosis. Vet Microbiol 2010, 140:287-296

4. World Health Organization: Human leptospirosis: guidance for diagnosis, surveillance and control. Malta: World health Organization; 2003.

5. Levett PN: Leptospirosis. Clin Microbiol Rev 2001, 14:296-326.

6. Bharti AR, Nally JE, Ricaldi JN, Matthias MA, Diaz MM, Lovett MA, Levett PN, Gilman RH, Willig MR, Gotuzzo E, Vinetz JM: Leptospirosis: a zoonotic disease of global importance. Lancet Infect Dis 2003, 3:757-771.

7. Faine S, Adler B, Bolin C, Pérolat P: Leptospira and leptospirosis. $2^{\text {nd }}$ edition. Melbourne, Australia: Medisci; 1999

8. Ko Al, Goarant C, Picardeau M: Leptospira: the dawn of the molecular genetics era for an emerging zoonotic pathogen. Nat Rev Microbiol 2009, 7:736-747.

9. Levett PN: Usefulness of serologic analysis as a predictor of the infecting serovar in patients with severe leptospirosis. Clin Infect Dis 2003, 36:447-452.

10. Smythe LD, Wuthiekanun V, Chierakul W, Suputtamongkol Y, Tiengrim S, Dohnt MF, Symonds ML, Slack AT, Apiwattanaporn A, Chueasuwanchai S, Day NP, Peacock SJ: The microscopic agglutination test (MAT) is an unreliable predictor of infecting Leptospira serovar in Thailand. Am J Trop Med Hyg 2009, 81:695-697.

11. Limmathurotsakul D, Turner EL, Wuthiekanun V, Thaipadungpanit J, Suputtamongkol Y, Chierakul W, Smythe LD, Day NPJ, Cooper B, Peacock SJ: Fool's gold: why imperfect reference tests are undermining the evaluation of novel diagnostics. A re-evaluation of five diagnostic tests for leptospirosis. Clin Infect Dis 2012, 55:322-331.

12. Derne BT, Fearnley EJ, Lau CL, Paynter S, Weinstein P: Biodiversity and leptospirosis risk: a case of pathogen regulation? Med Hypotheses 2011, 77:339-344.

13. Lau CL, Dobson AJ, Smythe LD, Fearnley EJ, Skelly C, Clements ACA, Craig SB, Fuimaono SD, Weinstein P: Leptospirosis in American Samoa 2010: epidemiology, environmental drivers, and the management of emergence. Am J Trop Med Hyg 2012, 86:309-319.

14. Goodman SM, Benstead J: The natural history of Madagascar. Chicago and London: University of Chicago Press; 2004

15. Desvars A, Naze F, Vourc'h G, Cardinale E, Picardeau M, Michault A, Bourhy P: Similarities in Leptospira serogroup and species distribution in animals and humans in the Indian Ocean island of Mayotte. Am J Trop Med Hyg 2012, 87:134-140.

16. Desvars A, Cardinale E, Michault A: Animal leptospirosis in small tropical areas. Epidemiol Infect 2011, 139:167-188.

17. Desvars A, Naze F, Benneveau A, Cardinale E, Michault A: Endemicity of leptospirosis in domestic and wild animal species from Reunion Island (Indian Ocean). Epidemiol Infect. in press.

18. de Abreu Fonseca C, Teixeirade Freitas VL, Romero EC, Spinosa C, Arroyo Sanches MC, Vinícius da Silva M, Shikanai-Yasuda MA: Polymerase chain reaction in comparison with serological tests for early diagnosis of human leptospirosis. Trop Med Int Health 2006, 11:1699-1707.

19. Moutou F: Enquête sur la faune murine dans le département de la Réunion. Saint-Denis (Reunion): Rapport DDASS; 1980 (in French).

20. Silverie R, Monnier M, Lataste-Dorolle C: Nouvelle enquête sur la leptospirose à Madagascar. Contribution à l'étude des leptospiroses humaines, bovines et porcines de la région sud. Bull Soc Pathol Exot Filiales 1968, 61:346-359 (in French). 
21. Bourhy $P$, Collet $L$, Lernout $T$, Zinini $F$, Hartskeerl RA, van der Linden $H$, Thiberge JM, Diancourt L, Brisse S, Giry C, Pettinelli F, Picardeau M: Human Leptospira isolates circulating in Mayotte (Indian Ocean) have unique serological and molecular features. J Clin Microbiol 2012, 50:307-311.

22. Simon F, Morand G, Roche C, Coton T, Kraemer P, Fournier P-E, Gautret P: Leptospirosis in a French traveler returning from Mauritius. J Travel Med 2012, 19:69-71.

23. Yersin $C$, Bovet $P$, Mérien $F$, Wong T, Panowsky J, Pérolat $P$ : Human leptospirosis in the Seychelles (Indian Ocean): a population-based study. Am J Trop Med Hyg 1998, 59:933-940.

24. Laporte P, Michault A, Galtier J, Lefait-Robin R, Aucher P, Baranton G: La leptospirose à Mayotte. Bull Soc Pathol Exot 1990, 83:637-641 (in French).

25. Bourhy P, Collet L, Clément S, Huerre M, Ave P, Giry C, Pettinelli F, Picardeau M: Isolation and characterization of new Leptospira genotypes from patients in Mayotte (Indian Ocean). PLoS Negl Trop Dis 2010, 4:e724.

26. Mailloux M, Debarbat F, Mollaret HH: Leptospiroses in the island of Reunion. I. Human leptospiroses. Bull Soc Pathol Exot 1983, 76:729-735 (in French).

27. Mailloux M: Identification of the first human Leptospira strain in the island of La Reunion. Bull Soc Pathol Exot 1985, 78:28-30 (in French).

28. Duval G, Michault A, Baranton G, Law-Koune JD, Folio G, Bertil G, Guiserix : Sero epidemiological survey on human leptospirosis in Reunion Island. Rev Epidemiol Sante Publique 1991, 39:135-141 (in French).

29. Yersin $C$, Bovet $P$, Mérien $F$, Clément J, Laille $M$, van Ranst $M$, Pérolat $P$. Pulmonary haemorrhage as a predominant cause of death in leptospirosis in Seychelles. Trans R Soc Trop Med Hyg 2000, 94:71-76.

30. Bovet $P$, Yersin $C$, Mérien $F$, Davis CE, Pérolat $P$ : Factors associated with clinical leptospirosis: a population-based case-control study in the Seychelles (Indian Ocean). Int J Epidemio/ 1999, 28:583-590.

31. Law-Koune JD, Duval G, Michault A, Baranton G, De Camaret P Lemahieu JM, Van-der-Linden T: Human leptospirosis in Reunion Island: epidemiological study during three years (1985-1987). Bull Soc Pathol Exot 1989, 82:185-191 (in French).

32. Mollaret HH, Mailloux M, Debarbat F: Leptospiroses in the island of Reunion. III. Epidemiological study. Bull Soc Pathol Exot 1983, 76:744-749 (in French).

33. Yersin C, Bovet $P$, Smits HL, Pérolat P: Field evaluation of a one-step dipstick assay for the diagnosis of human leptospirosis in the Seychelles. Trop Med Int Health 1999, 4:38-45.

34. Renault P, Boidin E, D'Ortenzio E, Balleydier E, Daniel B, Filleul L: Epidemiological surveillance of leptospirosis on Reunion Island in 20042008: possible impact of chikungunya infection on the case fatality rate of leptospirosis. Bull Soc Pathol Exot 2010, 104:148-152 (in French).

35. Desvars A, Gigan J, Hoarau G, Gérardin P, Favier F, Michault A: Seroprevalence of human leptospirosis in Reunion Island (Indian Ocean) assessed by microscopic agglutination test on paper disc-absorbed whole blood. Am J Trop Med Hyg 2011, 85:1097-1099.

36. Rahelinirina S, Léon A, Harstskeerl RA, Sertour N, Ahmed A, Raharimanana C, Ferquel E, Garnier M, Chartier L, Duplantier J-M, Rahalison L, Cornet M: First isolation and direct evidence for the existence of large small-mammal reservoirs of Leptospira sp. in Madagascar. PLoS One 2010, 5:e14111.

37. Charton A: Contribution à l'étude épidémiologique des leptospiroses. Le cas de lîle de Mayotte. PhD thesis. Université Claude Bernard: Ecole Nationale Vétérinaire de Lyon; 1992.

38. Sigaud M, Caceres S, Picard M, Desvars A, Michault A: Tailless tenrec (Tenrec ecaudatus): natural maintenance host of leptospires? Bull SoC Pathol Exot 2009, 102:19-20 (in French).

39. Gares H: Study of infertility risk factors in Reunion island dairy herds [in French]. Ecole Nationale Vétérinaire de Toulouse: Université Paul Sabatier; 2003.

40. Ralaiarijaona RL, Bellenger E, Chanteau S, Roger F, Pérolat P, Rasolofo Razanamparany $\mathrm{V}$ : Recherche de réservoirs de la leptospirose à Madagascar par la technique d'amplification génique. Arch Inst Pasteur Madagascar 2001, 67:34-36 (in French).

41. Debarbat F, Mollaret HH, Mailloux M: Leptospiroses in the island of Reunion. II. Animal leptospiroses. Bull Soc Pathol Exot 1983, 76:736-743 (in French).

42. Lagadec $E$, Gomard $Y$, Guernier $V$, Dietrich M, Pascalis $H$, Temmam $S$, Ramasindrazana B, Goodman SM, Tortosa P, Dellagi K: Pathogenic Leptospira spp. in Bats, Madagascar and Union of the Comoros. Emerg Infect Dis 2012, 18:1696-1698.
43. International Committee on Systematic Bacteriology, Sub-Committee on theTaxonomy of Leptospira: Minutes of the meeting 6-10 August 1982, Boston, Massachusetts. Int J Syst Bacteriol 1984, 34:258-259.

44. Buck G, Kolochine-Erber B, Quesnel J: Bovine leptospirosis should be suspected in Madagascar. Bull Soc Pathol Exot Filiales 1956, 49:681-686 (in French).

45. Rapports d'activité du centre national de référence des leptospiroses. [http://www.pasteur.fr/ip/easysite/pasteur/fr/sante/centres-nationaux-dereference-et-centres-collaborateurs-de-l-oms/cnr-et-ccoms/cnr-ccomsdes-leptospires/actualites-rapports].

46. Smythe LD, Field HE, Barnett LJ, Smith CS, Dohnt MF, Symonds ML, Moore MR, Rolfe PF: Leptospiral antibodies in flying foxes in Australia. J Wildl Dis 2002, 38:182-186.

47. Cox TE, Smythe LD, Leung LKP: Flying foxes as carrier of pathogenic Leptospira species. J Wildl Dis 2005, 41:753-757.

48. Tulsiani SM, Cobbold RN, Graham GC, Dohnt MF, Burns M-A, Leung LK-P Field HE, Smythe LD, Craig SB: The role of fruit bats in the transmission of pathogenic leptospires in Australia. Ann Trop Med Parasitol 2011, 105:71-84.

49. Matthias MA, Diaz MM, Campos KJ, Calderon M, Willig MR, Pacheco V, Gotuzzo E, Gilman RH, Vinetz JM: Diversity of bat-associated Leptospira in the Peruvian Amazon inferred by bayesian phylogenetic analysis of $16 \mathrm{~S}$ ribosomal DNA sequences. Am J Trop Med Hyg 2005, 73:964-974.

50. Bessa FTA, Spichler A, Berardis Chapola EG, Husch AC, Fernandes de Almeida M, Sodre MM, Mouriz Savani ESM, Veiga Sacramento DR, Vinetz JM: The contribution of bats to leptospirosis transmission in Sao Paulo city, Brazil. Am J Trop Med Hyg 2010, 82:315-317

51. Vashi NA, Reddy P, Wayne DB, Sabin B: Bat-associated leptospirosis. J Gen Intern Med 2010, 25:162-164.

52. Bunnel JE, Hice CL, Watts DM, Montrueil V, Tesh RB, Vinetz JM: Detection of pathogenic Leptospira spp. infections among mammals captured in the Peruvian Amazon basin region. Am J Trop Med Hyg 2000, 63:255-258.

53. Fennestad KL, Borg-Petersen C: Leptospirosis in Danish wild mammals. J Wildl Dis 1972, 8:343-351

54. Kolochine-Erber B, Brygoo ER: Research on leptospirosis in Madagascar Bull Soc Pathol Exot Filiales 1956, 49:686-698 (in French)

55. Lhuiller M: Leptospiroses in Madagascar (Bacteriological and serological study). Arch Inst Pasteur Madagascar 1978, 46:429-439 (in French).

56. Minette HP, Shaffer MF: Experimental leptospirosis in monkeys. Am J Trop Med Hyg 1968, 17:202-212.

57. Baulu J, Everard CO, Everard JD: Leptospires in vervet monkeys (Cercopithecus aethiops Sabaeus) on Barbados. J Wildl Dis 1987, 23:60-66.

58. Perolat P, Poingt J-P, Vie J-C, Jouaneau C, Baranton G, Gysin J: Occurrence of severe leptospirosis in a breeding colony of squirrel monkeys. Am J Trop Med Hyg 1992, 46:538-545.

59. Pereira MM, Da Silva JJP, Pinto MA, Da Silva MF, Machado MP, Lenzi HL, Marchevsky RS: Experimental leptospirosis in marmoset monkeys (Callithrix jacchus): a new model for studies of severe pulmonary leptospirosis. Am J Trop Med Hyg 2005, 72:13-20.

60. Freulon M, Aboubaker M, Marié JL, Drancourt M, Davoust B: Detection of Leptospira organisms in Rattus rattus of two islands in the Mozambique Channel: Europa and Juan-de-Nova. Bull Soc Pathol Exot 2010, 103:48-50 (in French).

61. Salles P, Brygoo ER, Saint-Amans P: A propos d'un cas de leptospirose humaine avec confirmation sérologique observé à Madagascar. Arch Inst Pasteur Madagascar 1955, 19:23 (in French).

62. Gamage CD, Tamashiro H, Ohnishi M, Koizumi N: Epidemiology, surveillance and laboratory diagnosis of leptospirosis in the WHO SouthEast Asia region. In Zoonosis. Edited by Lorenzo-Morales DJ. Rijeka, Croatia: InTech Europe; 2012:213-226

63. D'Aoust L, Munbodh P, Sookram C, Paratian U, Gaüzère BA, Aubry P: Status report on public health in Mauritius in 2009. Med Trop 2010, 70:229-238 (in French)

64. Pinn T: Leptospirosis in the Seychelles. Med J Aust 1992, 156:163-167.

65. Mailloux M: Human leptospiroses in the overseas departments and territories: 10 years' immunological diagnosis (1970-1979). Bull Soc Pathol Exot Filiales 1980, 73:229-238 (in French).

66. Cellule Interrégionale d'Epidémiologie Océan Indien: La leptospirose à La Réunion en 2009. Saint-Denis (Reunion): CIRE Océan Indien; 2010.

67. Rakotomalala R, Tiaray M, Borgherini G, Andrianarisoa A, Rasamindrakotroka A: Should leptospirosis be suspected in several feverish pneumopathy? Revue d'Anesthésie-Réanimation et de Médecine d'Urgence 2010, 2:1-3 (in French). 
68. Paganin F, Bourdin A, Dalban C, Courtin JP, Poubeau P, Borgherini G Michault A, Sally JC, Tixier F, Genin R, Arvin-Berod C: Leptospirosis in Reunion Island (Indian Ocean): analysis of factors associated with severity in 147 confirmed cases. Intensive Care Med 2007, 33:1959-1966.

69. Paganin F, Bourdin A, Borgherini G, Dalban C, Poubeau P, Tixier F, Gouix A Noel J-B, Cotte L, Arvin-Berod C: Pulmonary manifestations of leptospirosis. Rev Mal Respir 2009, 26:971-979.

70. Prescott JF, Miller RB, Nicholson VM, Martin SW, Lesnick T: Seroprevalence and association with abortion of leptospirosis in cattle in Ontario. Can $J$ Vet Res 1988, 52:210-215.

71. Higgins RJ, Harbourne JF, Little TW, Stevens AE: Mastitis and abortion in dairy cattle associated with Leptospira of the serotype hardjo. Vet Rec 1980, 107:307-310.

72. Langoni H, de Souza LC, da Silva AV, Luvizotto MCR, Paes AC, Lucheis SB: Incidence of leptospiral abortion in Brazilian dairy cattle. Prev Vet Med 1999, 40:271-275.

73. Sykes JE, Hartmann K, Lunn KF, Moore GE, Stoddard RA, Goldstein RE: ACVIM small animal consensus statement on leptospirosis: diagnosis, epidemiology, treatment, and prevention. J Vet Intern Med 2010, 2010:1-13.

74. Meeyam T, Tablerk P, Petchanok B, Pichpol D, Padungtod P: Seroprevalence and risk factors associated with leptospirosis in dogs. Southeast Asian J Trop Med Public Health 2006, 37:148-153.

75. Boqvist S, Chau BL, Gunnarsson A, Olsson Engvall E, Vågsholm I, Magnusson U: Animal- and herd-level risk factors for leptospiral seropositivity among sows in the Mekong delta, Vietnam. Prev Vet Med 2002, 53:233-245.

76. Schoonman L, Swai ES: Herd- and animal-level risk factors for bovine leptospirosis in Tanga region of Tanzania. Trop Anim Health Prod 2010, 42:1565-1572.

77. Lilenbaum W, Varges R, Medeiros L, Cordeiro AG, Cavalcanti A, Souza GN, Richtzenhain $\sqcup$, Vasconcellos AS: Risk factors associated with leptospirosis in dairy goats under tropical conditions in Brazil. Res Vet Sci 2008, 84:14-17.

78. Lilenbaum W, Souza GN: Factors associated with bovine leptospirosis in Rio de Janeiro, Brazil. Res Vet Sci 2003, 75:249-251.

79. dos Santos J, Lima-Ribeiro A, Oliveira P, dos Santos M, Júnior Á, Medeiros A, Tavares T: Seroprevalence and risk factors for leptospirosis in goats in Uberlândia, Minas Gerais, Brazil. Trop Anim Health Prod 2012, 44:101-106.

80. Sarkar U, Nascimento S, Barbosa R, Martins R, Nuevo H, Kalafanos I, Grunstein I, Flannery B, Dias J, Riley LW, Reis MG, Ko Al: Population-based case-control investigation of risk factors for leptospirosis during an urban epidemic. Am J Trop Med Hyg 2002, 66:605-610.

81. Coelho M, Massad E: The impact of climate on leptospirosis in São Paulo, Brazil. Int J Biometeorol 2011, 56:233-241.

82. Herrmann-Storck C, Brioudes A, Quirin R, Deloumeaux J, Lamaury I, Nicolas M, Postic D, Perez JM: Retrospective review of leptospirosis in Guadeloupe, French West Indies 1994-2001. West Indian Med J 2005, 54:42-46

83. Pappachan MJ, Sheela M, Aravindan KP: Relation of rainfall pattern and epidemic leptospirosis in the Indian state of Kerala. J Epidemiol Community Health 2004, 58:1054-1055.

84. Desvars A, Jégo S, Chiroleu F, Bourhy P, Cardinale E, Michault A: Seasonality of human leptospirosis in Reunion island (Indian Ocean) and its association with meteorological data. PLOS One 2011, 6:e20377.

85. Tassinari WS, Pellegrini DCP, Sá CBP, Reis RB, Ko Al, Carvalho MS: Detection and modelling of case clusters for urban leptospirosis. Trop Med Int Health 2008, 13:503-512.

86. Marotto PCF, Ko Al, Murta-Nascimento C, Seguro AC, Prado RR, Barbosa MC, Cleto SA, Eluf-Neto J: Early identification of leptospirosis-associated pulmonary hemorrhage syndrome by use of a validated prediction model. J Infect 2010, 60:218-223.

87. Koizumi N, Muto M, Tanikawa T, Mizutani H, Sohmura Y, Hayashi E, Akao N, Hoshino M, Kawabata H, Watanabe H: Human leptospirosis cases and the prevalence of rats harbouring Leptospira interrogans in urban areas of Tokyo, Japan. J Med Microbiol 2009, 58:1227-1230.

88. Kawabata H, Sakakibara S, Imai Y, Masuzawa T, Fujita H, Tsurumi M, Sato F, Takano A, Nogami S, Kaneda K, Watanabe H: First record of Leptospira borgpetersenii isolation in the Amami Islands, Japan. Microbiol Immunol 2006, 50:429-434.

89. Villanueva SYAM, Ezoe $H$, Baterna RA, Yanagihara Y, Muto M, Koizumi N, Fukui T, Okamoto Y, Masuzawa T, Cavinta LL, Gloriani NG, Yoshida S: Serologic and molecular studies of Leptospira and leptospirosis among rats in the Philippines. Am J Trop Med Hyg 2010, 82:889-898.
90. Scialfa E, Bolpe J, Bardón JC, Ridao G, Gentile J, Gallicchio O: Isolation of Leptospira interrogans from suburban rats in Tandil, Buenos Aires, Argentina. Rev Argent Microbiol 2010, 42:126-128.

91. Tollenaere C, Brouat C, Duplantier JM, Rahalison L, Rahelinirina S, Pascal M Moné H, Mouahid G, Leirs H, Cosson JF: Phylogeography of the introduced species Rattus rattus in the western Indian Ocean, with special emphasis on the colonization history of Madagascar. J Biogeog 2010, 37:398-410.

92. Desvars A: Epidemiology of a zoonose, leptospirosis, in two Indian Ocean islands, Reunion Island and Mayotte - Comparative study of the role of some wild and domestic species (in French). PhD thesis. Saint-Denis University (Reunion), Epidemiology Department; 2012.

93. Barragan VA, Mejia ME, Trávez A, Zapata S, Hartskeerl RA, Haake DA, Trueba GA: Interactions of Leptospira with environmental bacteria from surface water. Curr Microbiol 2011, 62:1802-1806.

94. Jena $A B$, Mohanty KC, Devadasan N: An outbreak of leptospirosis in Orissa, India: the importance of surveillance. Trop Med Int Health 2004, 9:1016-1021.

95. Vinetz JM, Wilcock BA, Aguirre A, Gollin LX, Katz AR, Fujioka RS, Maly K, Horwitz P, Chang H: Beyond disciplinary boundaries: leptospirosis as a model of incorporating transdisciplinary approaches to understand infectious disease emergence. Ecohealth 2005, 2:291-306.

96. Bezirtzoglou C, Dekas K, Charvalos E: Climate changes, environment and infection: facts, scenarios and growing awareness from the public health community within Europe. Anaerobe 2011, 17:337-340.

97. Barcellos C, Sabroza PC: The place behind the case: leptospirosis risks and associated environmental conditions in a flood-related outbreak in Rio de Janeiro. Cad Saude Publica 2001, 17:S59-S67.

98. Sanders EJ, Rigau-Perez JG, Smits HL, Deseda CC, Vorndam VA, Aye T, Spiegel RA, Weyant RS, Bragg SL: Increase of leptospirosis in denguenegative patients after a hurricane in Puerto Rico in 1996 [correction of 1966]. Am J Trop Med Hyg 1999, 61:399-404.

99. Gaynor K, Katz AR, Park SY, Nakata M, Clark TA, Effler PV: Leptospirosis on Oahu: an outbreak associated with flooding of a university campus. Am J Trop Med Hyg 2007, 76:882-886.

100. Patz JA, Kovats RS: Hotspots in climate change and human health. Br Med J 2002, 325:1094-1098.

doi:10.1186/1297-9716-44-80

Cite this article as: Desvars et al:: Leptospirosis in the western Indian Ocean islands: what is known so far? Veterinary Research 2013 44:80.

\section{Submit your next manuscript to BioMed Central and take full advantage of:}

- Convenient online submission

- Thorough peer review

- No space constraints or color figure charges

- Immediate publication on acceptance

- Inclusion in PubMed, CAS, Scopus and Google Scholar

- Research which is freely available for redistribution

Submit your manuscript at www.biomedcentral.com/submit
C) Biomed Central 